Sikirynska D. O., Hudyma A. A., Pokhodun K. A., Antonyshyn I. V. Influence of cranioskeltal trauma, complicated with blood loss, on the bile-forming function of liver during the early period of traumatic disease among rats with different resistance to hypoxia and its correction. Journal of Education, Health and Sport. 2021;11(1):326-337. eISSN 2391-8306. DOI http://dx.doi.org/10.12775/JEHS.2021.11.1.032

https://apcz.umk.pl/czasopisma/index.php/JEHS/article/view/JEHS.2021.11.1.032

https://zenodo.org/record/5106652

8

The journal has had 5 points in Ministry of Science and Higher Education parametric evaluation. \$ 8. 2) and \$ 12. 1.2) 22.02.2019.

$\odot$ The Authors 2021;
This article is published with open access at Licensee Open Journal Systems of Nicolaus Copernicus University in Torun, Poland

This article is published with open access at Licensee Open Journal Systems of Nicolaus Copernicus University in Torun, Poland
Open Access. This article is distributed under the terms of the Creative Commons Attribution Noncommercial License which permits any noncommercial use, distribution, and reproduction in any medium, provided the original author (s) and source are credited. This is an open access article licensed under the terms of the Creative Commons Attribution Non commercial license Share alike. The authors declare that there is no conflict of interests regarding the publication of this paper.
The

Received: 25.12.2020. Revised: 14.12.2020. Accepted: 29.01.2021.

UDC 616.711/.714-001.3-005.1-036.4:616.36-008.8]-085-092.9

\title{
INFLUENCE OF CRANIOSKELTAL TRAUMA, COMPLICATED WITH BLOOD LOSS, ON THE BILE-FORMING FUNCTION OF LIVER DURING THE EARLY PERIOD OF TRAUMATIC DISEASE AMONG RATS WITH DIFFERENT RESISTANCE TO HYPOXIA AND ITS CORRECTION
}

\author{
D. O. Sikirynska, A. A. Hudyma, K. A. Pokhodun, I. V. Antonyshyn
}

\section{Horbachevsky Ternopil National Medical University Ministry of Health of Ukraine}

\section{Abstract}

Introduction. The development of multiorgan dysfunction and insufficiency is one of the serious complications of severe multiple and combined lesions. In their pathogenesis, a key role is played by secondary lesions of organs remote from the site of direct injury, which is caused by the systemic response of the body to inflammation and is a characteristic feature of traumatic disease. As a model of the development of organ damage in experimental polytrauma, the biliary function of liver is often investigated. However, the features of systemic disorders, in particular, the biliary function of liver, in conditions of severe skeletal injury, depending on the resistance to hypoxia, have not been studied enough.

Purpose: to determine the dynamics of biliary function of liver in case of cranioskeletal trauma complicated with blood loss among rats with different resistance to hypoxia during the early period of traumatic disease and to evaluate the effectiveness of thiocetam in the correction of identified disorders. 
Materials and methods. 108 nonlinear white male rats weighing 180-200 g were used in the experiments. Previously, individual resistance to hypoxia was determined, rats were divided into two groups: with high- and low-resistance (HR and LR) animals to hypoxia. Subsequently, HR and LR rats were divided into 4 groups: one control and three experimental. Under conditions of thiopentale sodium anesthesia $\left(40 \mathrm{mg} \mathrm{kg}^{-1}\right)$ the first experimental group HR and LR of rats was had cranioskeletal trauma, the second - acute blood loss in the amount of 20-22\% of circulating blood volume, the third experimental group after application of cranioskeletal injuries and acute blood loss in order to correct HR and LRrats were thrown Thiocetam intraperitoneally, dose $250 \mathrm{mg} \mathrm{kg}^{-1}$ of body weight 1 time per day. Animals of the control and experimental groups in 1, 3 and 7 days after injury were catheterized the common bile duct, collected bile, in which the content of total bile acids was determined.

It was found out that laboratory white rats, which are genetically different in resistance to hypoxia, also differ in the intensity of biliary function of liver. Among HR rats, the bile content of total bile acids was higher than that among LR rats. Under the influence of cranioskeletal injury, the bile content of total bile acids decreased among both HR and LR rats. Despite the lower initial content of total bile acids in the bile of LR rats, under the influence of cranioskeletal trauma in this group, the degree of the studied indicator reduction was significantly greater than among HR rats, indicating greater sensitivity of LR rats to pathogens of traumatic disease, which lead to damage to the microsomal monooxygenase system of hepatocytes. Under the conditions of acute blood loss additional modeling, the disorders were more visible, but the result was statistically significant only among LR rats in 3 days of the experiment. In addition, LR rats had a greater degree of reduction of the studied indicator in 3 and 7 days of the experiment. Under the influence of seven-day-usage of Thiocetam in the groups of LR and HR rats with cranioskeletal trauma, the violation of total bile acids content in the bile became significantly lower compared to animals without correction. A similar result was found under conditions of additional acute blood loss. Under these conditions, the degree of increase of total bile acids content in the bile was greater among LR rats than among HR rats, which indicates a higher efficiency of Thiocetam among LR rats.

Conclusions: 1 . The content of total bile acids in the bile among intact HR-rats is significantly higher than among LR-rats. Under the influence of cranioskeletal trauma, the content of total bile acids in the bile is reduced compared to the control, but the degree of reduction is significantly greater among LR rats after 7 days of the experiment. Complication 
of cranioskeletal injury with acute blood loss causes a significantly greater reduction in the bile content of total bile acids among LR rats compared with HR rats after 3 and 7 days of the experiment. The use of Thiocetam is accompanied by a decrease of liver biliary dysfunction, which is more visible among LR rats with acute blood loss.

Key words: cranioskeletal trauma; blood loss; resistance to hypoxia; bile-forming function of liver; Thiocetam.

Introduction. The development of multiorgan dysfunction and insufficiency is one of serious complications of severe multiple and combined lesions. In their pathogenesis, a key role is played by secondary lesions of organs remote from the site of direct injury, which is caused by the systemic response of the body to inflammation and is a characteristic feature of traumatic disease [1].

As a model of the development of organ damage in experimental polytrauma, the biliary function of liver is often studied, in particular the concentration of total bile acids and conjugated bilirubin in bile [2], which are organ-specific features of the functional state of liver and are related to the functional capacity of the microsomal hepatocyte system, in which the main synthetic and detoxification processes take place [3]. In particular, [4] the work shows that in the acute period and the period of early manifestations of traumatic disease in the case of cranioskeletal trauma there is a violation of biliary function of liver, manifested by decreased bile secretion and excretion of total bile acids, cholesterol, total and direct bilirubin with a minimum 7 days after injury. The revealed disturbances deepen after additional acute blood loss. In the pathogenesis of the identified disorders, the authors perceive the influence of liver hypoxia, which occurs due to impaired microcirculation and decreased blood supply of the organ with the activation of lipid peroxidation and degradation of endoplasmic membranes.

It is known that one of the constitutional features of the mammalian body is resistance to hypoxia. However, the features of systemic disorders, in particular biliary function of liver, under conditions of severe skeletal injury, depending on the resistance to hypoxia, have not been studied enough. Giving the leading role to hypoxia in the pathogenesis of polytrauma, we can assume a different course of traumatic disease among animals with high- and lowresistance to hypoxia.

Purpose: to determine the dynamics of liver biliary function in the case of cranioskeletal trauma complicated with blood loss among rats with different resistance to 
hypoxia during the early period of traumatic disease and to evaluate the effectiveness of thiocetam in the correction of the identified disorders.

Materials and methods. 108 nonlinear white male rats weighing 180-200 g were used in the experiments. All animals were on a standard vivarium diet. Previously, according to the method described in the work [5], rats were exemined for individual resistance to hypoxia and two groups were identified: high- and low-resistant (HR and LR) to hypoxia animals. In 14 days, HR and LR rats were divided into 4 groups: one control (6 intact hypoxia-resistant rats), and three experimental. Under thiopental sodium anesthesia (40 $\mathrm{mg} \mathrm{kg}^{-1}$ ) in the first experimental group HR and LR rats (36 animals) simulated cranioskeletal trauma by sequential application of a dosed stroke to the skull with the achievement of closed craniocerebral trauma of moderate severity and dosed stroke on the thigh by percussion device with a wedge-shaped nozzle to achieve a closed hip fracture [6]. In the second experimental group, HR and LR-rats (36 animals) under conditions of asepsis and antiseptics additionally simulated acute blood loss in the amount of $20-22 \%$ of the circulating blood volume by crossing the femoral vein [7]. In the third experimental group after application of cranioskeletal trauma and acute blood loss for the purpose of correction of HR and LR rats (24 animals) were intraperitoneally administered Thiocetam (JSC "Halychpharm", Lviv, Ukraine), dose of $250 \mathrm{mg} \mathrm{kg}^{-1}$ body weight once a day [8].

The biliary function of liver was studied among animals of the experimental groups 1 , 3 and 7 days after injury, which corresponded to the acute period and the period of early manifestations of traumatic disease. Under thiopental-sodium anesthesia $\left(60 \mathrm{mg} \mathrm{kg}^{-1}\right)$, the common bile duct was catheterized in animals and bile was collected for 1 hour. The content of total bile acids was determined in the obtained bile [3]. Animals in the control group were only thrown under thiopental sodium anesthesia, bile secretion function was studied after 1 day.

In order to neutralize the effect on the result of different content of total bile acids in HR- and LR-rats of the control group, in addition to the absolute values of the studied indicator, the ratio of individual values of indicators in groups to the average value of the control group is calculated. This allowed us to assess the statistical significance of the deviation degree of the studied indicator in the groups of HR and LR. We also calculated the average ratio of individual values of total bile acids in the group of animals with correction to the average value of the animal group without correction to assess the statistical significance of the deviation degree of the studied indicator among animals treated with Thiocetam compared with animals without correction. 
During the work with laboratory animals, international requirements for the humane treatment with animals were complied in accordance with the rules of the European Convention for the Protection of Vertebrate Animals Used for Experimental and Other Scientific Purposes (European Convention, 1984). Euthanasia of rats after bile collection was performed by total bloodletting from the heart.

Statistical analysis of the results was performed using the Mann-Whitney test in the software package STATISTICA 10.0 ("StatSoft, Inc.", USA).

Research results and their discussion. As can be seen from table 1, in the control group of HR rats, the bile content of total bile acids was statistically significantly higher than that of $\mathrm{LR}$ rats (by 30,2\%, p <0,05).

Table 1 - Dynamics of total bile acids content $\left(\mathrm{g} \cdot \mathrm{l}^{-1}\right)$ in response to cranioskeletal trauma complicated by blood loss among animals with different resistance to hypoxia (Me (LQ; UQ)) - median (lower and upper quartiles)

\begin{tabular}{|c|c|c|c|c|}
\hline \multirow{2}{*}{$\begin{array}{l}\text { Resistance to } \\
\text { hypoxia }\end{array}$} & \multirow[t]{2}{*}{ Control } & \multicolumn{3}{|c|}{ The term of the post-traumatic period } \\
\hline & & 1 day & 3 day & 7 day \\
\hline \multicolumn{5}{|c|}{ Cranioskeletal trauma } \\
\hline Low-resistant & $\begin{array}{c}2,48 \\
(2,29 ; 2,55) \\
(\mathrm{n}=6)\end{array}$ & $\begin{array}{c}2,18^{*} \\
(1,99 ; 2,25) \\
(n=7)\end{array}$ & $\begin{array}{c}1,88^{* 1 д} \\
(1,69 ; 1,95) \\
(n=7)\end{array}$ & 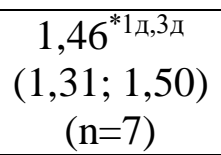 \\
\hline Highly resistant & $\begin{array}{c}3,23^{\#} \\
(3,15 ; 3,41) \\
(n=6)\end{array}$ & $\begin{array}{c}2,78^{* \#} \\
(2,48 ; 2,96) \\
(n=8)\end{array}$ & $\begin{array}{c}2,51^{* \#} \\
(2,42 ; 2,78) \\
(n=10)\end{array}$ & $\begin{array}{c}2,33^{* \#} \\
(2,14 ; 2,51) \\
(n=10)\end{array}$ \\
\hline \multicolumn{5}{|c|}{ Cranioskeletal trauma + blood loss } \\
\hline Low-resistant & $\begin{array}{c}2,48 \\
(2,29 ; 2,55) \\
(\mathrm{n}=6)\end{array}$ & $\begin{array}{c}1,95^{*} \\
(1,95 ; 2,06) \\
(\mathrm{n}=6)\end{array}$ & $\begin{array}{c}1,43^{* 1 д} \\
(1,24 ; 1,50) \\
(n=6)\end{array}$ & $\begin{array}{c}1,20^{\text {*1д }} \\
(1,20 ; 1,28) \\
(n=5)\end{array}$ \\
\hline Highly resistant & $\begin{array}{c}3,23^{\#} \\
(3,15 ; 3,41) \\
(\mathrm{n}=6)\end{array}$ & $\begin{array}{c}2,51^{* \#} \\
(2,31 ; 2,66) \\
(\mathrm{n}=8)\end{array}$ & $\begin{array}{c}2,36^{* \#} \\
(2,27 ; 2,51) \\
(n=9)\end{array}$ & 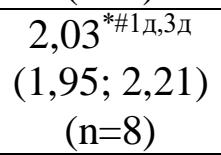 \\
\hline \multicolumn{2}{|r|}{$(2, x)$} & $>0,05$ & $<0,05$ & $>0,05$ \\
\hline \multicolumn{2}{|c|}{$\mathrm{p}_{2}$} & $>0,05$ & $>0,05$ & $>0,05$ \\
\hline
\end{tabular}

Notes. Here and in other tables:

1. * - differences relative to the control group are statistically significant $(\mathrm{p}<0,05)$;

2. \# - differences between groups of HR and LR animals are statistically significant $(\mathrm{p}<0,05)$;

3. $1 \mathrm{~d}, 3 \mathrm{~d}$ - differences in relation to 1 and 3 days of observation are statistically significant $(\mathrm{p}<0,05)$;

4. $\mathrm{p}_{1}$ - the probability of differences in groups of emergencies of LR animals with and without additional blood loss;

5. $\mathrm{p}_{2}$ - the probability of differences in the groups of HR animals with existing and no additional blood loss; 
Under the influence of cranioskeletal trauma among LR rats, the bile content of total bile acids decreased: after 1 day - by 12,1\%, after 3 days - by 24,2\%, after 7 days - by 41,1\%. In all terms of the post-traumatic period, the differences were statistically significant compared with the control $(\mathrm{p}<0,05)$. Among HR rats, the indicator also decreased statistically significantly compared with the control: by $13,9,22,2$ and $27,9 \%$, accordingly (p <0,05). Comparison of the studied indicator value between the experimental groups showed that in all periods of the post-traumatic period among HR rats, the absolute value of the studied indicator was significantly higher than among LR rats $(27,5,33,5$ and 59,6\%, accordingly, $\mathrm{p}<$ $0,05)$.

Analysis of the average ratio dynamics of individual bile contents of total bile acids to the average value of the control group showed (Table 2) that after 1 and 3 days the differences between the experimental groups were statistically not significant ( $p>0,05)$. At the same time, after 7 days, the value of the studied indicator in the group of HR-rats was significantly higher (by $22,0 \%, \mathrm{p}<0,05$ ).

Table 2 - Dynamics of the average ratio of individual values of bile flow rate to the average value of the control group in response to cranioskeletal trauma complicated by blood loss among animals with different resistance to hypoxia (Me (LQ; UQ)) - median (lower and upper quartiles)

\begin{tabular}{|c|c|c|c|}
\hline \multirow{2}{*}{$\begin{array}{c}\text { Resistance to } \\
\text { hypoxia }\end{array}$} & \multicolumn{3}{|c|}{ The term of the post-traumatic period } \\
\cline { 2 - 4 } & 1 day & 3 day & 7 day \\
\hline \multirow{3}{*}{ Low-resistant } & \multicolumn{4}{|c|}{ Cranioskeletal trauma } \\
& 0,88 & 0,76 & 0,59 \\
& $(0,80 ; 0,91)$ & $(0,68 ; 0,79)$ & $(0,53 ; 0,60)$ \\
$(\mathrm{n}=7)$ & $(\mathrm{n}=7)$ & $(\mathrm{n}=7)$ \\
\hline \multirow{3}{*}{ Highly resistant } & 0,86 & 0,78 & $0,72^{\#}$ \\
& $(0,77 ; 0,92)$ & $(0,75 ; 0,86)$ & $(0,66 ; 0,78)$ \\
& $(\mathrm{n}=8)$ & $(\mathrm{n}=10)$ & $(\mathrm{n}=10)$ \\
\hline \multirow{4}{*}{ Low-resistant } & Cranioskeletal trauma + blood loss \\
& 0,79 & 0,57 & 0,48 \\
& $(0,79 ; 0,83)$ & $(0,50 ; 0,60)$ & $(0,48 ; 0,51)$ \\
$(\mathrm{n}=7)$ & $(\mathrm{n}=7)$ & $(\mathrm{n}=7)$ \\
\hline \multirow{3}{*}{ Highly resistant } & 0,78 & $0,73^{\#}$ & $0,63^{\#}$ \\
& $(0,71 ; 0,82)$ & $(0,70 ; 0,78)$ & $(0,60 ; 0,68)$ \\
$(\mathrm{n}=8)$ & $(\mathrm{n}=10)$ & $(\mathrm{n}=10)$ \\
\hline
\end{tabular}

Simulation of additional blood loss among animals with cranioskeletal trauma also led to a statistically significant decrease in the content of total bile acids in bile (Table 1): among LR animals, accordingly, by $21,4,42,3$ and $51,6 \%$ ( $p<0,05)$ among HR rats - by 22,3, 26,9 
and $37,2 \%$, accordingly ( $\mathrm{p}<0,05)$. Comparison of experimental groups showed that during all periods of the post-traumatic period in the group of HR-rats the value of the studied indicator was significantly lower than among LR-rats (accordingly 28,7, 65,0 and 69,2\%, p <0,05).

Analysis of the average ratio dynamics of individual bile contents of total bile acids to the average value of the control group showed (Table 2) that after 1 day the differences between the experimental groups were statistically not significant ( $p>0,05)$. At the same time, after 3 and 7 days, the value of the studied indicator in the group of HR rats was significantly higher (by 28,1 and 31,2\%, p <0,05, accordingly).

Groups comparison of LR rats with cranioskeletal trauma depending on the presence or absence of acute blood loss showed that under conditions of acute blood loss, the bile content of total bile acids became statistically significantly lower only after 3 days of the experiment (by $23,9 \%, \mathrm{p}_{1}<0,05$ ). Among HR rats with cranioskeletal trauma, additional blood loss also led to a decrease in the value of the studied indicator, but the result during all periods of the post-traumatic period was not statistically significant $\left(\mathrm{p}_{2}>0,05\right)$.

Under conditions of correction with Thiocetam after 7 days, the content of total bile acids in the bile of animals, which simulated only cranioskeletal trauma (Fig. 1), increased: among LR animals - by 28,7\% (p<0,05), among HR- rats - by 19,3\% (p<0,05).

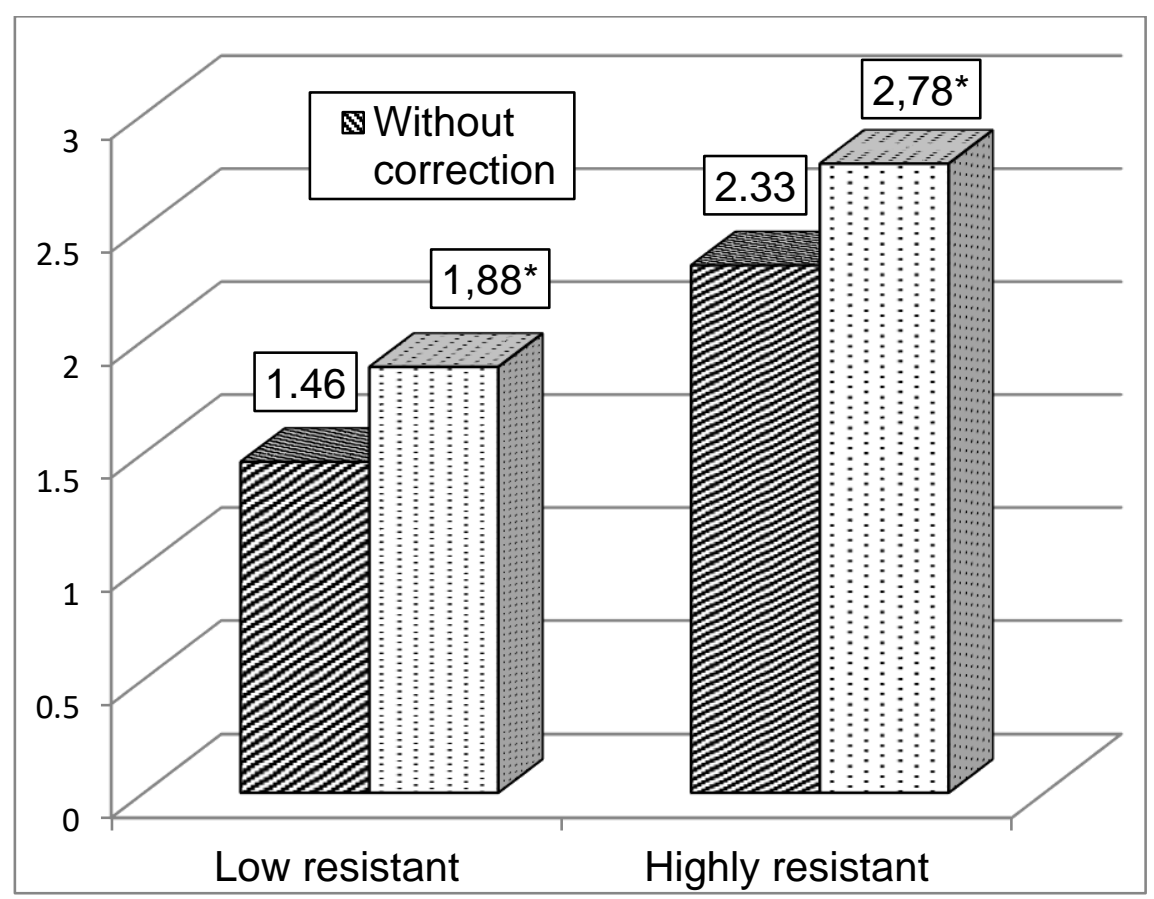

Figure 1 - The effect of Thiocetam on the content of total bile acids in the bile $\left(\mathrm{g} \cdot \mathrm{1}^{-1}\right)$ 7 days after modeling of cranioskeletal trauma among animals with different resistance to hypoxia (Here and in Fig. 2:* - differences in the group of animals without statistical correction probable, $\mathrm{p}<0,05)$. 
Animals, which were additionally were simulated acute blood loss, the rate also increased under the influence of Thiocetam, (Fig. 2): among LR animals by 50,0\% ( $p<0,05$ ), among HR rats - by $29,6 \%<0,05)$.

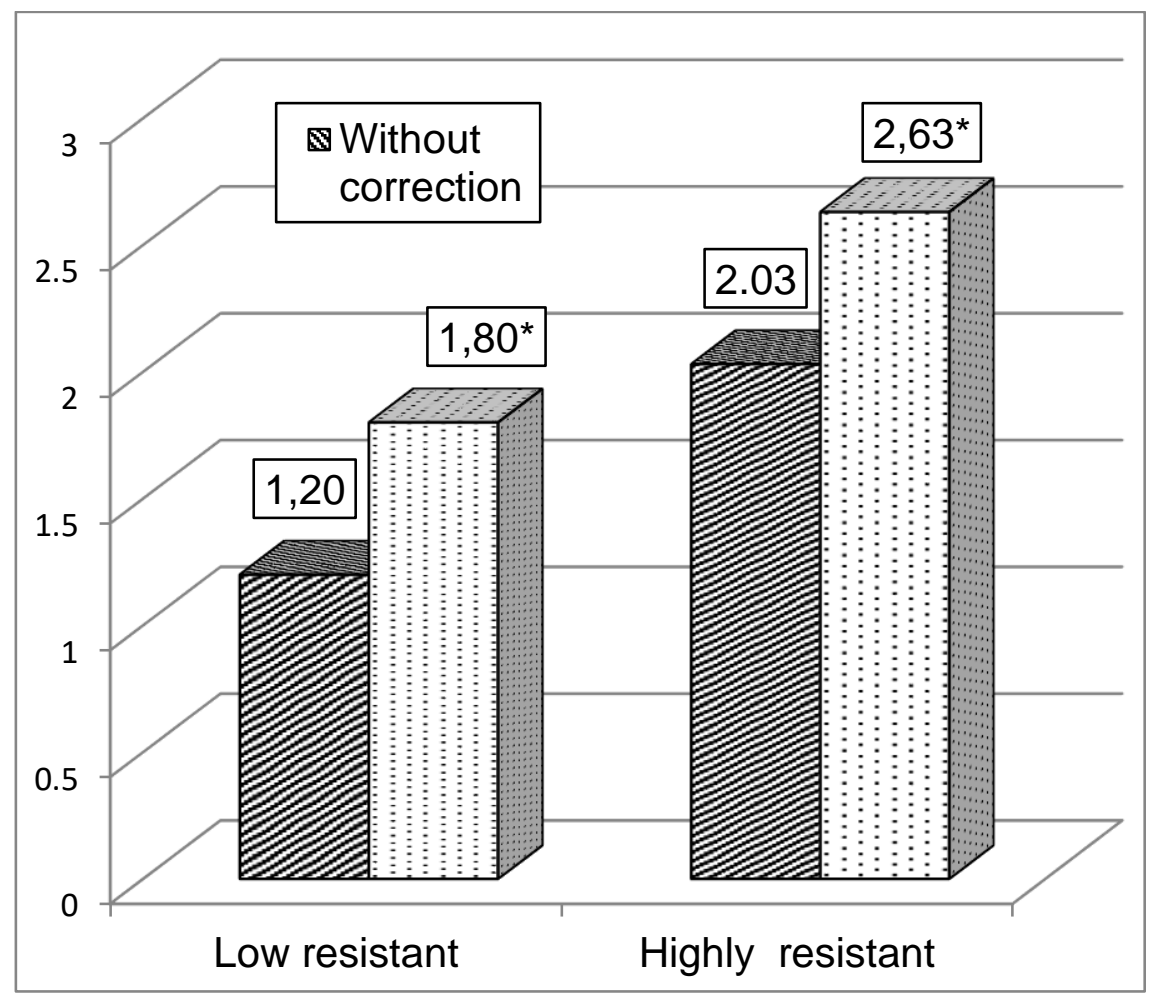

Figure 2 - The effect of Thiocetam on the content of total bile acids in the bile $\left(\mathrm{g} \cdot \mathrm{l}^{-1}\right) 7$ days after modeling of cranioskeletal trauma complicated by blood loss among animals with different resistance to hypoxia.

Estimation of the average ratio of individual bile contents of total bile acids in the group of animals with correction to the average value of animals without correction showed (Fig. 3) that the degree of increase in bile content of total bile acids under the influence of Thiocetam among animals with different resistance to hypoxia, which simulated only cranioskeletal trauma, did not differ ( $p>0,05)$, although there was a tendency to a larger value in the group of LR animals. However, under conditions of additional blood loss, the rate was statistically significantly higher among LR rats compared with HR rats (by 16,3\%, p <0,05).

The obtained results indicate that laboratory white rats, which are genetically different by the degree of resistance to hypoxia, also differ by the intensity of bile-forming function of the liver. Among HR rats, the bile content of total bile acids was higher than that of LR rats. It is known that in the process of bile acids synthesis from cholesterol the leading role is played by the membranes state of the hepatocytes microsomal system. In this regard, it can be argued that the functional activity of hepatocyte microsomes is higher among HR rats. Given the 
broad substrate specificity of hepatocyte microsome enzymes [9], it can be assumed that the metabolic capacity of hepatocytes is greater among HR rats. The last, in turn, is also genetically determined, which allowed among rats to identify fast and slow metabolizers [10]. During control these authors also found a higher content of total bile acids among fastmetabolizing rats.

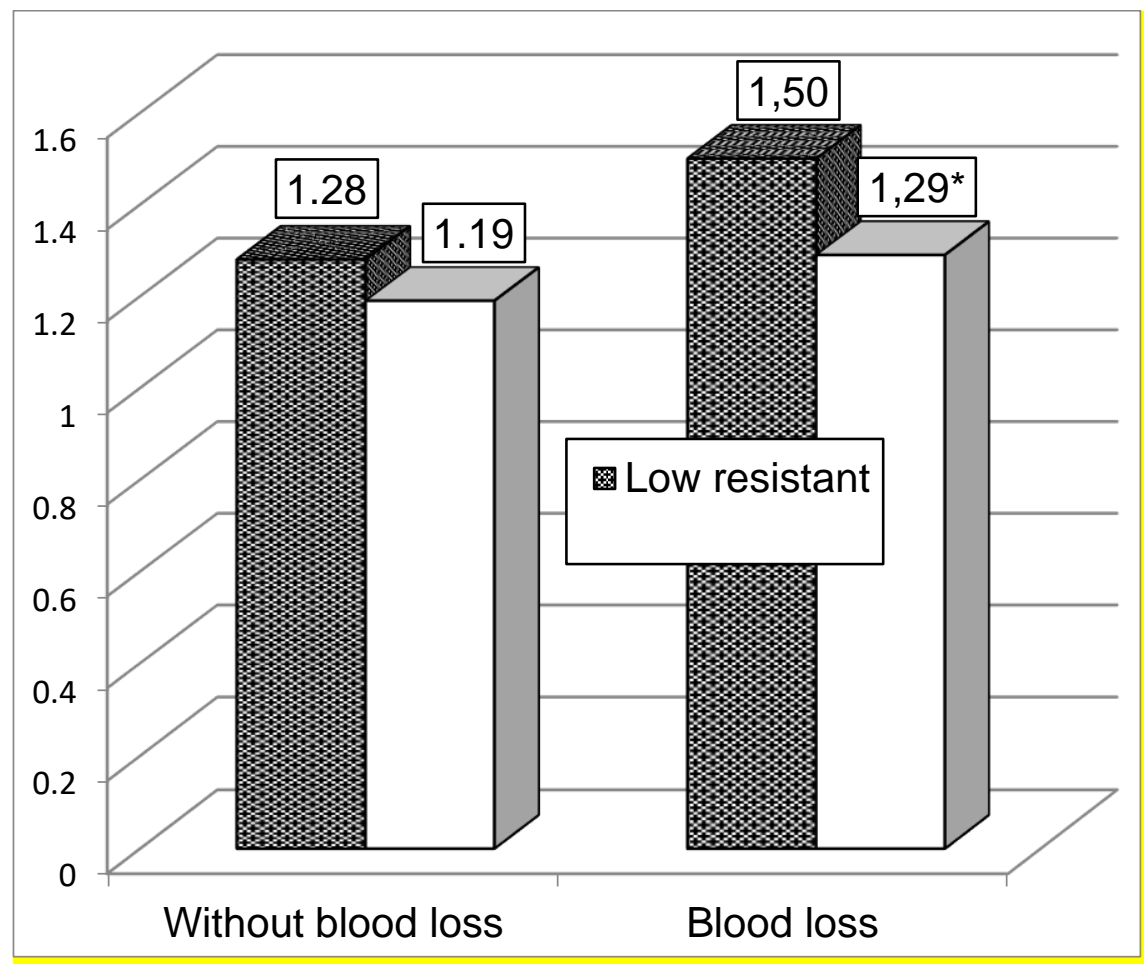

Figure 3 - Dynamics of the average ratio of individual values of bile secretion in a group of animals with correction to the average value of animal group without correction under the condition of cranioskeletal trauma modeling complicated by blood loss among highand low-resistant animals to hypoxia.

Under the influence of cranioskeletal trauma, the bile content of total bile acids decreased among both LR rats and HR rats. This is probably due to the damage tof the membranes of the microsomal enzyme hepatocytes by reactive oxygen species and free radicals, as it is shown in the works of other authors [11]. Despite the lower initial content of total bile acids in the bile of LR rats, under the influence of cranioskeletal trauma in this group, the degree of reduction of the studied index was significantly greater than among HR rats, indicating greater sensitivity of LR rats to pathogens of traumatic disease. which lead to the affection of the microsomal monooxygenase system of hepatocytes [12].

Under additional simulation of acute blood loss, the disorders were more visible, but the result was statistically significant only among LR rats after 3 days of the experiment, 
indicating a greater impact of hypoxemia due to blood loss on the functional state of liver. An additional confirmation of this was the greater degree of reduction of the studied indicator among LR rats, which was statistically significant after 3 and 7 days of the experiment. It can be assumed that among LR rats, hypoxia is a key pathogenic factor of cranioskeletal trauma and blood loss, which contribute to the slowing of the hepatocytes metabolic function, in particular its bile-forming function.

In order to correct the detected disorders, we used the medication Thiocetam, which, as shown by our previous studies [13], proved to be effective in the correction of lipid peroxidation disorders, antioxidant protection and cytolysis. Studies have shown that under the influence of seven-day use of Thiocetam in groups of LR and HR rats with cranioskeletal trauma disorders of the total bile acids in bile became significantly smaller compared to animals without correction. A similar result was found under conditions of additional acute blood loss. Analysis of the deviation degree of the studied indicator among animals injected with Thiocetam, compared with animals without correction, showed that the degree of increase in total bile acids in bile among LR rats was greater than among HR rats, which was statistically significant in terms of additional blood loss. Thus, the efficiency of Thiocetam among LR rats was higher compared to HR rats, which requires further preclinical studies.

Conclusions: 1 . The content of total bile acids in bile, as a basic indicator of bileforming function of liver, among intact HR rats is significantly higher than among LR rats.

2. Under the influence of cranioskeletal trauma, the content of total bile acids in bile is probably reduced compared to control in the groups of LR and HR rats, but the degree of reduction is significantly greater among LR rats after 7 days of post-traumatic period.

3. Complication of cranioskeletal trauma by acute blood loss causes a significantly greater decrease in the bile content of total bile acids among LR rats compared with HR rats after 3 and 7 days of the experiment.

4. Usage of Thiocetam is accompanied by a decrease in the disorders of bile-forming function of liver among LR and HR rats with cranioskeletal trauma, which is more visible among LR rats with acute blood loss.

Prospects for further research. In the future, it is necessary to investigate the structural differences of liver among animals with different resistance to hypoxia with cranioskeletal trauma complicated by blood loss.

\section{References}

1. Kalinkin O.G. Traumatic disease. Trauma. 2013. T. 14, № 3. URL: http://www.mif-ua.com/archive/article/36559. 
2. Kozak D.V. Peculiarities of bile-forming function of liver in the dynamics of polytrauma in the experiment. Journal of Health Sciences. 2013. Vol. 3, № 12. pp 241-256.

3. Preclinical studies of drugs: guidelines; edited by Corresponding Member Academy of Medical Sciences of Ukraine O.V. Stefanov. K.: Avicenna, 2001. 528 p.

4. Zayets T. A., Gudyma A. A. Peculiarities of liver functional state in the early period of cranioskeletal injury combined with bleeding, and its correction by cell therapy. Journal of Health Sciences. 2014. Vol. 4, No 1. pp. 383-390.

5. Saturska G.S., Bondarenko Iu. I. Peculiarities of connective tissue metabolism in experimental diffuse ischemic-necrotic cardiosclerosis among rats with different resistance to hypoxia. Bulletin of VNMU. 2014. T. 18, № 2. pp. 425-429.

6. Borys R.M., Gozhenko A.I., Hudyma A.A. Dynamics of lipid peroxidation indicators during the period of early and late manifestations of traumatic disease under the conditions of experimental cranioskeletal trauma and its correction with cell therapy. Clinical and experimental pathology. 2013. T. XII, № 2 (44). pp. 31-34.

7. Influence of two-hour tourniquets ischemia of limb and acute blood loss on systemic disorders of the body in the reperfusion period (experimental study) / I. I. Horban, A. A. Hudyma, R. V. Maksymiv, I. V. Antonyshyn. Wiadomości Lekarskie. 2020. Vol. LXXIII, Iss. 7. pp. 1330-1333.

8. Mykhailiuk I.A., Hudyma A.A. Metabolic disorders of liver in the late period of cranioskeletal trauma and their correction by thiocetam. Medical and clinical chemistry. 2015. T. 17, № 2. pp. 56-58.

9. Microsomal oxidation in physiological and pathological processes / E. E. Kuznetsova, V.G. Gorokhova, A.G. Gorokhov [etc.]. Bulletin of ESSC SD RAMS. 2007. № 4 (56). pp. $170-180$.

10. Hudyma A.A., Iarema V.V. Violation of bile formation and bile secretion in the early period of polytrauma among animals with different metabolic capacity of liver. Achievements of clinical and experimental medicine. 2012. № 2 (17). pp. 48-52.

11. Zayets T. A., Gudyma A. A. Peculiarities of liver functional state in the early period of cranioskeletal injury combined with bleeding, and its correction by cell therapy. Journal of Health Sciences. 2014. Vol. 4, No 1. pp. 383-390.

12. Kozak D. V. Lipid peroxidation, antioxidant defence, endogenous intoxication and cytolysis variations in early and late manifestations of traumatic disease. Journal of Health Sciences. 2013. Vol. 3, № 4. pp. 108-117. 
13. Sikirynska D.O. Influence of thiocetam on the course of the early period of cranioskeletal trauma among animals with different resistance to hypoxia. Current issues of pharmacology and pharmacotherapy: materials all-Ukrainian. scientific-practical Conf., Sept. 26-27. 2019. Ternopil: TNMU, 2019. pp. 65-66. 